\title{
Elementary Particles and Astrotheology
}

\section{Cusack PTE}

1641 Sandy Point Rd, Saint John, NB, E2K 5E8, Canada

\begin{abstract}
In this paper, we consider the elementary particles in the light of Astro-Theology. We see that these two branches of physics can be united using well known chemistry equations. A Pressure and a Temperature equation are derived, as well as spin and charge equations.
\end{abstract}

Keywords: Ideal Gas Law; Charles Law; Temperature Equation; Pressure Equation; Elementary particles

\section{Introduction}

Uniting Cosmology and quantum mechanics has been a goal of physicists for a century. F we consider the works in Astro-theology, Cusack's Universe, and the elementary particles, we can see that these two systems can be combined mathematically $[1,2]$. Here we examine Mass in terms of micro and macro physics. We use the standard Chemistry equations to see that the micro and macro can be combined into one model of the universe. We begin with the macro and move to the micro.

$$
\begin{aligned}
& \mathrm{e}^{-\pi}=0.4321 \\
& \operatorname{Ln} \pi=1.1447 \\
& 1 /\left[\mathrm{e}^{-\pi}-\operatorname{Ln} \pi\right]=1 / 2=0.500
\end{aligned}
$$

Now, from Chemistry, the Ideal Gas Law and Charles's law (Figure 1)

$\mathrm{PV}=\mathrm{nRT}$

$\mathrm{P}_{1} \mathrm{~V}_{1} / \mathrm{T}_{1}=\mathrm{P}_{2} \mathrm{~V}_{2} / \mathrm{T}_{2}$

$\mathrm{PV}=\mathrm{nR}=(6.023)(8.31)=5.005=1 / 1998=\mathrm{Y}($ Dampened Cosine $)$

$\mathrm{Y}=\mathrm{e}^{-\mathrm{t}} \cos (2 \pi \mathrm{t})$

Let $\mathrm{t}=1$

$\mathrm{Y}=\mathrm{e}^{-1} \cos (2 \pi)$

$=0.3657=1 / 273.47=1 / \mathrm{K} \quad($ Kelvin=Temperature $)$

Therefore

$\mathrm{Y}=1 / \mathrm{K}$

$\mathrm{E}=1 / \mathrm{K}$ and $\mathrm{K}=1 / \mathrm{E}=\mathrm{t}$

$\mathrm{PV}=\mathrm{nRT}$

$=(6.023)(8.31)(273.47)$

$=0.13468$

$=1-0.8631$

$=1-[1 / 115.86]$.

\section{Cusack's Pressure Equation}

$$
\mathrm{PV}=1-[1 / \mathrm{M}]
$$$$
\mathrm{P}=\mathrm{F} / \mathrm{A}
$$

Area $=\pi R^{2}$
Volume $=4 / 3 \pi R^{3}$

Area $=$ Volume

$\mathrm{R}=3 / 4=0.75=1 / \mathrm{s}$

When $\cos t=0, t=\pi / 2 ; 3 \pi / 2$

$2 \pi \mathrm{t}=3 \pi / 2$

$\mathrm{t}=0.75=\mathrm{R}=1 / \mathrm{s}$

$273.47=\mathrm{n}(0.75)$

$\mathrm{n}=364.62$

$364.62-273.47=91.15^{\circ} \mathrm{C} \sim \mathrm{c}^{2}$

364.62/ $\pi=116.02=$ Mass (Periodic Table)

\section{Cusack's Temperature Equation}

$\mathrm{K}=\mathrm{Mt}$

$\mathrm{E}=\mathrm{Mc}^{2}$

$=(116)(91.15)$

$=105.79$

$105.79 /(0.4233)^{3}$

$=1394.76$

$=86.05=1 / \mathrm{M}$

For a Bottom Quark which has $\mathrm{E}=4.18 \mathrm{GV} / \mathrm{c}^{2}$, explained in Figure 2

This is Mass $4.233 \mathrm{~J} / \mathrm{kg} / 0.418 \mathrm{~kg}=1.0127 \mathrm{~J}=\mathrm{E}$

101.27 J $/ 91.15 \mathrm{C}=1 / 9.00069=(1 / 3)^{2}=$ Charge $^{2}[=] \mathrm{J}^{2} / \mathrm{kg}$

$1 / \mathrm{c}=$ Charge $[=] \mathrm{J} / \mathrm{kg}$

Charge $=1 / \mathrm{c}=$ time $/$ distance $=1 /(4 / 3)=0.75=1 / \mathrm{s}=\mathrm{K}=\mathrm{t}$

$1 /$ Charge $/$ spin $=1 /(-1 / 3) /(1 / 2)=-6$

*Corresponding author: Cusack PTE, Independent Researcher, 1641 Sandy Point Rd, Saint John, NB, E2K 5E8, Canada, Tel: 506-214-3313; E-mail: St-Michael@hotmail.com

Received August 03, 2017; Accepted October 02, 2017; Published October 05 2017

Citation: Cusack PTE (2017) Elementary Particles and Astrotheology. J Phys Math 8: 246. doi: 10.4172/2090-0902.1000246

Copyright: @ 2017 Cusack PTE. This is an open-access article distributed under the terms of the Creative Commons Attribution License, which permits unrestricted use, distribution, and reproduction in any medium, provided the original author and source are credited. 


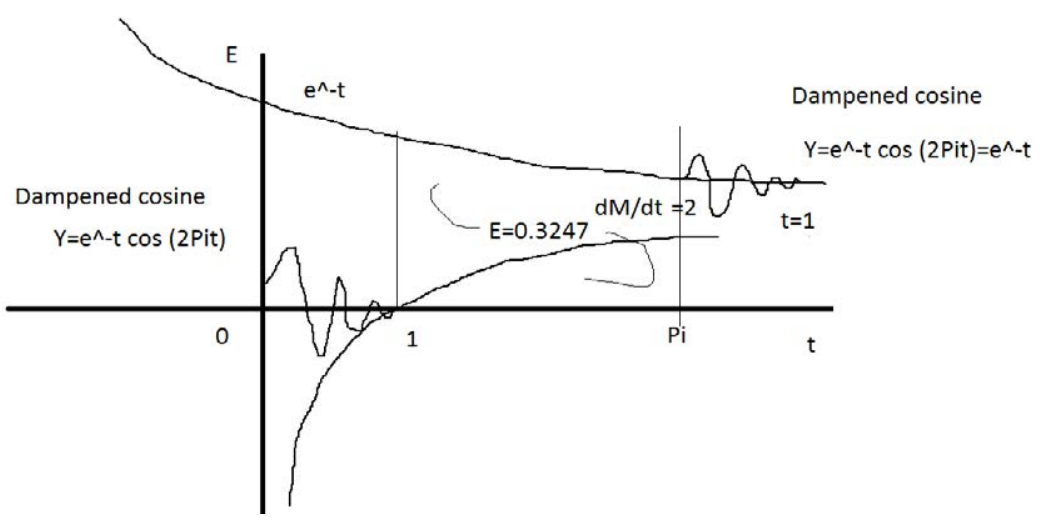

Figure 1: Mass formation.

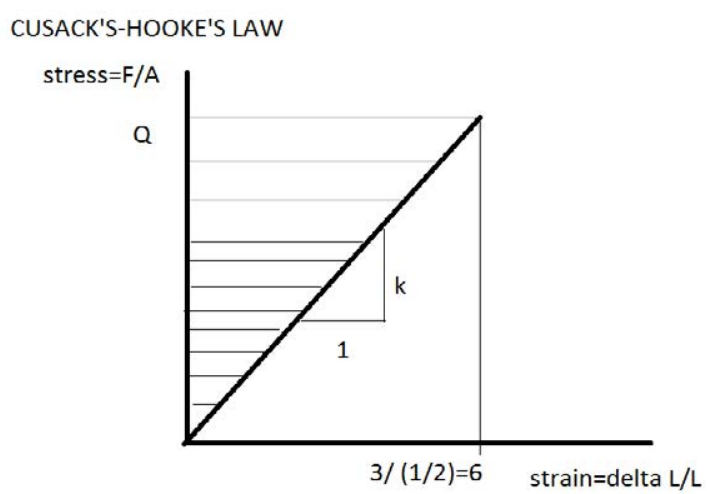

Figure 2: Cusack-Hook's law for resistance to mass.

Spin $[=] 1 /[$ charge $\mathrm{x}$ strain] $=1 /$ charge

Spin $=$ Charge $\left[60 / 360^{\circ}\right]$

Spin $=1 / \mathrm{c}(1 / 6)$

Spin $=1 / 6 c)=0.555=1 / 18$

Spin $=1 / 18=0.1313=1-\sin 60^{\circ}=$ Moment

Charge $=1 /$ spin $=6 c=18$

Spin $=1 /$ Charge $=6 \mathrm{c}=$ Moment

For a Muon Lepton Mass $=105.67 \mathrm{MeV} / \mathrm{c}^{2}$

This is energy $=\mathrm{Mc}^{2}$

For a $\mathbf{Z}$ Boson Mass $91.19 \mathrm{GeV} / \mathrm{c}^{2}$

This is Temperature above $0^{\circ}$ Celsius $[3,4]$.

Higgs Scalar Bosons and Golden mean parabola:

$(125.09)^{2}-(1.2509)-1=-0.686$

$(1.2509)^{2}-(1.2509)-1=1+\pi$

$=4.139$

$4.139-4.18=0.041$

41 is the $14^{\text {th }}$ Prime Number

Riemann Hypothesis rationalizing Prime Numbers [5]
$\mathrm{Y}=\mathrm{e}^{\mathrm{z}}+\mathrm{Ln} \pi$

$=\mathrm{e}^{14}+\operatorname{Ln} \pi=1 / 0.8315=1 / \mathrm{R}$ (The Gas Constant $[=] \mathrm{J} / \mathrm{mol} . \mathrm{K}$ )

Now consider the equation of the universe (Figure 3)

$t^{3}-6 t+3=E$

$\mathrm{E}=1$

$\delta=\Delta \mathrm{L} / \mathrm{L}=6$

Charge $=\mathrm{Ch} .=3$

$\mathrm{Et}^{3}-\delta \mathrm{t}+\mathrm{Ch} .=\mathrm{E}$

$\mathrm{E}(1 / \mathrm{E})^{3}-\Delta \mathrm{L}(\mathrm{t} / \mathrm{L})+\mathrm{Ch} .=\mathrm{E}$

$1 / \mathrm{E}^{2}-\Delta \mathrm{L} / \mathrm{v}+\mathrm{Ch} .=\mathrm{E}$

$\left.1 /(1)^{2}-1 / 1 / \sqrt{ } 2\right)+3=\mathrm{E}$

$1-\sqrt{2}+3=2.5858$

$=1 / 0.3867$

$=\mathrm{e}^{-0.95}$

$=\mathrm{e}(-1 / 1.0597)$

$=\mathrm{e}^{-\mathrm{t}}$

Aside:

$-0.95=-1 / 1.0597$ 


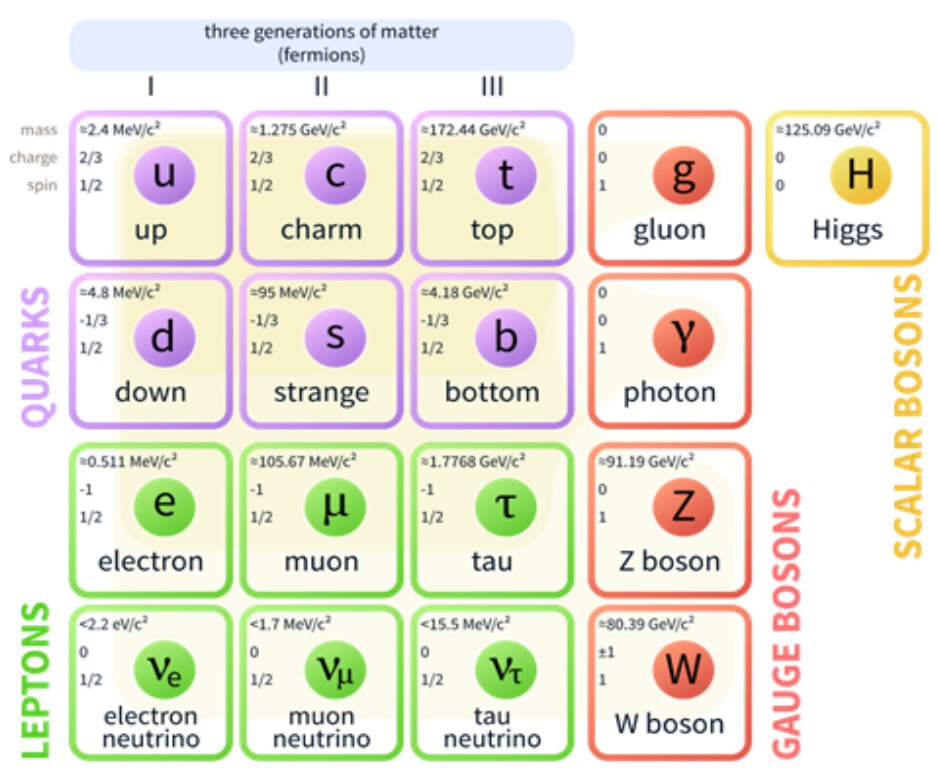

Figure 3: Elementary particles.

$$
-1.0597=-\mathrm{E}=\mathrm{Mc}^{2}=-(116)(91.15)=-\mathrm{MK}=-1 / \mathrm{t}=-\left(\mathrm{t}^{-1}\right)
$$

Therefore, the equation is: $\mathrm{Et}^{3}-\delta \mathrm{t}+\mathrm{Ch} .=\mathrm{e}^{-\mathrm{t}}$.

\section{Conclusion}

So the Energy is stored in the Muon; the Temperature is stored in the Z Boson; and the mass is stored in the Bottom Quark. The Spin is the inverse of the charge, the charge is $1 / c$. The Temperature is the equal to the time and inverse of space. The spin causes the charge by the conservation of angular momentum. Astro-theology and Quantum mechanics are united.

\section{References}

1. Cusack P (2016) Astrotheology Cusack's Universe. Journal of Physical Mathematics 7: 1-8.

2. Causack P (2017) Cosmology, Mass and the Super Force. Fluid Mech Open Acc 4: 1-161.

3. The Riemann hypothesis Clay Institute Problem Solution. J Appl Computat Math 5: 1-317.

4. Mechanics of Materials for Astro-theology.

5. Causack $P$ (2017) The Universal Vector Space and Static Equilibrium Techniques. Fluid mechanics Open Access 4: 1-5 